\title{
Comparative Evaluation of the Depth of Penetration of different Types of Desensitizing Agents into the Dentinal Tubules: An in vivo Study
}

\author{
${ }^{1}$ Aditya Mitra, ${ }^{2}$ Chandrani Adhikari
}

\begin{abstract}
Aim: Aim of the study is to evaluate the depth of penetration of different types of desensitizing agents into the dentinal tubules in vivo.
\end{abstract}

Materials and methods: Twenty patients requiring tooth extraction for orthodontic purpose were selected. In all four premolars of the selected patients, small class $\mathrm{V}$ cavities were prepared on the buccal surface having depth of $0.5 \mathrm{~mm}$. They were divided into four groups and treated with four different types of desensitizing agents ( $5 \% \mathrm{NaF}$ solution, Gluma desensitizer, FluorProtector, and SuperSeal) for required time and then they were extracted. They were longitudinally sectioned and each section was studied by scanning electron microscope.

Results: The mean depth of penetration of SuperSeal and Gluma was significantly higher than that of other agents (sodium fluoride and FluorProtector) $(p<0.05)$. No significant difference was found between SuperSeal and Gluma ( $p>0.05$ ).

Conclusion: The depth of penetration of resinous desensitizing agent (Gluma) is maximum followed by potassium oxalate solution (SuperSeal) and fluoride varnish (FluorProtector).

Clinical significance: Deeper the penetration of desensitizing agents into the dentinal tubules, longer the efficacy.

Keywords: Dentinal tubules, Depth of penetration, Desensitizing agents.

How to cite this article: Mitra A, Adhikari C. Comparative Evaluation of the Depth of Penetration of different Types of Desensitizing Agents into the Dentinal Tubules: An in vivo Study. J Contemp Dent 2017;7(1):43-47.

Source of support: Nil

Conflict of interest: None

\section{INTRODUCTION}

Cervical dentin hypersensitivity $(\mathrm{CDH})$ can be defined as an exaggerated response to the stimulation of vital dentin

\footnotetext{
${ }^{1}$ Professor, ${ }^{2}$ Dental Surgeon

${ }^{1}$ Department of Conservative Dentistry and Endodontics, Guru Nanak Institute of Dental Science \& Research and Hospital Kolkata, West Bengal, India

${ }^{2}$ Department of Dentistry, R. G. Kar Medical College \& Hospital Kolkata, West Bengal, India

Corresponding Author: Aditya Mitra, Professor, Department of Conservative Dentistry and Endodontics, Guru Nanak Institute of Dental Science \& Research and Hospital, Kolkata, West Bengal India, Phone: +919830066371, e-mail: adityamjjm@gmail.com
}

exposed to the oral environment, which causes extreme discomfort and is characterized by short-term, acute pain of variable intensity. The $\mathrm{CDH}$ occurs in response to thermal, volatile, tactile, osmotic, or chemical stimuli that cannot be attributed to any other type of defect or dental pathology. These distressing stimuli can be produced by the ingestion of hot or cold food and beverages, acidic foods, sometimes by toothbrushing. This sensation (pain) can be localized or generalized, affecting one or more tooth surfaces and generally ceases immediately after removal of the stimulus. ${ }^{1}$

The etiology and mechanisms underlying the development of dentin hypersensitivity have not yet been well explained. Various theories have been propounded in an attempt to explain the mechanism involved in the generation of pain and transmission of the stimuli through dentin out of which Hydrodynamic Theory [Brännström (1966) is most accepted. This theory claims loss of overlying enamel and/or cementum results in the dentinal tubules barely exposed to the oral environment, and then the presence of certain stimuli causes the displacement of fluids within the tubules, indirectly stimulating the pulp nerve endings and causing the sensation of pain. According to this theory, if the radius of opened dentinal tubules can be reduced, then the permeability of the dentinal tubule is also reduced, ${ }^{2}$ thereby the sensitivity is decreased. Thus, treatments for hypersensitivity should occlude the open dentinal tubules and prevent nerve sensitivity. ${ }^{1,3}$ Other methods include nerve desensitization (by using potassium nitrate) and laser.

The degree of dentinal hypersensitivity can be clinically evaluated by thermal stimulus, air blast, or tactile sensation, and the patient's response can be detected by visual analog scale. But the degree of response varies from patient to patient as different patients have different degrees of tolerance. That is why it is not a very reliable method to detect the degree of sensitivity and how much the sensitivity is reduced after the desensitizing therapy. But if the degree of penetration of the desensitizing agents into the dentinal tubules can be measured, then it can be a criterion for long-standing action and success. The depth of penetration of the desensitizing agents into 
the dentinal tubules should be an important criteria in long-term success of the treatment because deeper the penetration of desensitizing agents into the dentinal tubules, longer the efficacy.

Therefore, the purpose of the study is to determine the depth of penetration of four different desensitizing agents within the dentinal tubules.

\section{MATERIALS AND METHODS}

This research was conducted after being approved by the Institution's Ethical Committee on Research involving human beings following the principles of Helsinki declaration by the World Medical Association. The patients signed a form of free and informed consent and were informed of the events during and after the study.

Twenty patients who require extraction for orthodontic purpose (four maxillary and mandibular first premolars) were selected. In each patient, four teeth are treated with sodium fluoride, Gluma, SuperSeal, and FluorProtector respectively. The materials used in the present study are tabulated below:

\begin{tabular}{ll}
\hline No. & Materials \\
\hline 1 & $\begin{array}{l}5 \% \text { sodium fluoride [Dey's Medical Stores (Mfg.) Limited, } \\
\text { Kolkata] }\end{array}$ \\
2 & $\begin{array}{l}\text { Gluma desensitizer (Heraeus Kulzer, USA) [5\% } \\
\text { glutaraldehyde and 35\% hydroxyethyl methacrylate, } \\
\text { benzalkonium chloride] }\end{array}$ \\
3 & $\begin{array}{l}\text { SuperSeal (Phoenix Dental, USA) (solution of potassium } \\
\text { oxalate dihydrate containing 1.5-10\% by weight of } \\
\text { potassium oxalate dihydrate salt) }\end{array}$ \\
4 & $\begin{array}{l}\text { FluorProtector (Ivoclar Vivadent) (0.9\% difluorsilane in a } \\
\text { polyurethane varnish base with ethyl acetate and isoamyl } \\
\text { propionate solvents) }\end{array}$ \\
\hline
\end{tabular}

- All the compositions are written as per manufacturer's information.

\section{SELECTION OF PATIENTS}

\section{Inclusion Criteria}

- Patients for orthodontic treatment who require extraction of premolar teeth

- Young adults of second and third decade

\section{Exclusion Criteria}

- Patients presently on desensitizing treatment

- Tooth with carious lesion

- Tooth with gingival recession, detectable fracture/ crack

- Tooth with abrasion/erosion/abfraction

- Tooth with exposed dentinal tubules (preoperatively)

- Subjects with preexisting orthodontic appliances or fixed partial denture that may interfere with the study
Oral prophylaxis was done on selected patients. Rubber dam was used to isolate the premolar tooth to be treated. Class V cavity was prepared on the buccal surface of first premolar of either side of both arches (occlusal wall $4 \mathrm{~mm}$, gingival wall $3 \mathrm{~mm}$, axial wall $1.5 \mathrm{~mm}$, and axial depth $0.5 \mathrm{~mm}$ ).

Four teeth of each patient were placed into four different groups randomly.

Group I - 5\% sodium fluoride

Group II - Gluma (resinous desensitizing agent)

Group III - SuperSeal (potassium oxalate solution)

Group IV - FluorProtector (fluoride varnish)

All the desensitizing agents were applied on the prepared class $\mathrm{V}$ cavity for 1 minute and repeated for thrice with 1-minute interval. The teeth were then extracted after 48 hours and stored in normal saline. Then the cervical region of the teeth were sectioned longitudinally by diamond disk and the specimens were dried and placed on aluminum stub by using a carbon putty. Then aluminum stub with the specimens were placed in a gold splutter coater machine for 100 seconds to coat the mounted specimens in gold before they go into the scanning electron microscope (SEM). Then the samples were examined with SEM to determine the depth of penetration of desensitizing agents within the dentinal tubules.

\section{RESULTS}

In the SEM, it was observed that the depth of penetration of sodium fluoride into the dentinal tubule was very less (Fig. 1), followed by FluorProtector (Fig. 2), SuperSeal (Fig. 3), and Gluma (Fig. 4). The depth of penetration of Gluma and SuperSeal was much higher than sodium fluoride and FluorProtector.

From the SEM study, the data regarding the depth of penetration of four desensitizing agents were obtained. Statistical analysis was done.

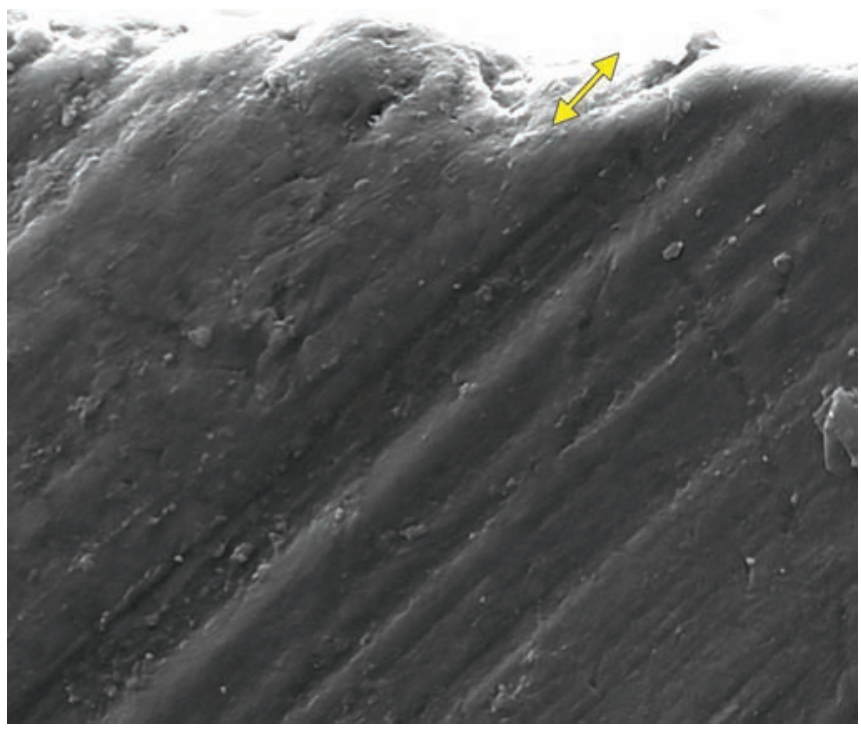

Fig. 1: Depth of penetration of sodium fluoride 


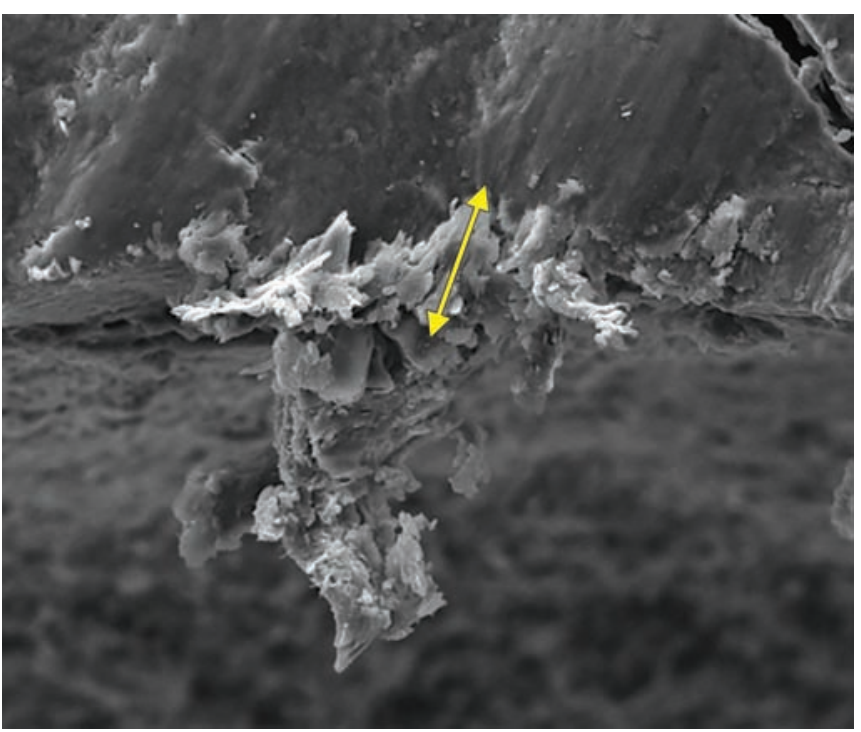

Fig. 2: Depth of penetration of FluorProtector

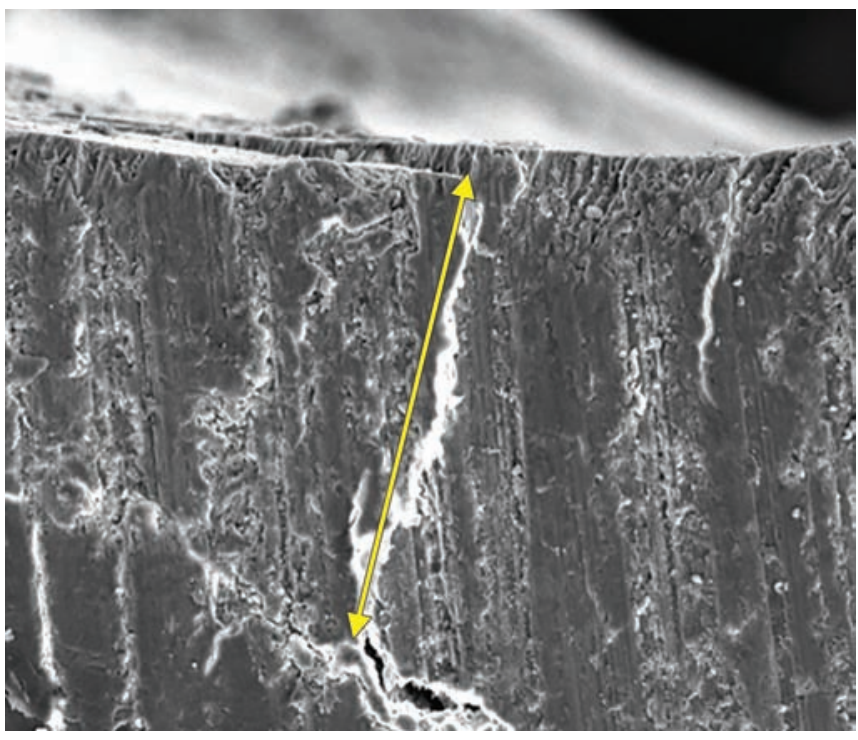

Fig. 4: Depth of penetration of Gluma

\section{Statistical Analysis}

Statistical analysis was performed with help of Epi Info ${ }^{\mathrm{TM}}$ 3.5.3. Epi Info is a trademark of the Centers for Disease Control and Prevention.

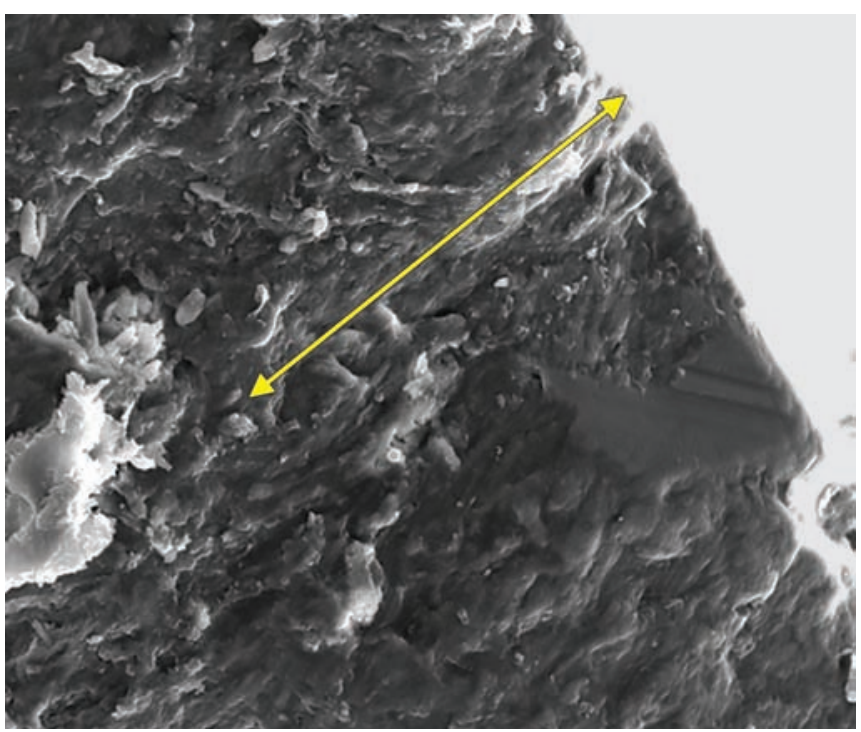

Fig. 3: Depth of penetration of SuperSeal

Descriptive statistical analysis was performed to calculate the means with corresponding standard deviations (SDs). Also, one-way analysis of variance (ANOVA) followed by Tukey's test was performed with the help of critical difference (CD) or least significant difference at 5 and $1 \%$ level of significance to compare the mean values; $\mathrm{p} \leq 0.05$ was taken to be statistically significant.

Mean $\pm S D$, median, and range of depth of penetration (in $\mu \mathrm{m}$ ) of different types of desensitizing agents are shown in Table 1.

The ANOVA showed that there was significant difference in depth of penetration of different types of desensitizing agents in first round experiment $\left(\mathrm{F}_{3,13}=\right.$ 10.84; $\mathrm{p}=0.0007$ ) (Table 2).

The depth of penetration of different desensitizing agents in $\mu \mathrm{m}$ are shown in Graph 1.

\section{Differences of Mean}

As per the CD, the mean depth of penetration of SuperSeal was significantly higher than that of sodium fluoride $(p<0.05)$ and mean depth of penetration of Gluma was significantly higher than that of sodium fluoride $(p<0.01)$. No

Table 1: Mean \pm SD, median, and range of depth of penetration (in $\mu \mathrm{m}$ ) of different types of desensitizing agents

\begin{tabular}{lllll}
\hline Values of descriptive statistics & Sodium fluoride & FluorProtector & SuperSeal & Gluma \\
\hline Mean \pm SD & $9.03 \pm 3.41$ & $21.23 \pm 8.91$ & $73.05 \pm 33.60$ & $101.69 \pm 31.75$ \\
Median & 9.03 & 20.40 & 70.56 & 107.47 \\
Range (Minimum - Maximum) & $6.62-11.44$ & $11.67-32.89$ & $33.03-111.42$ & $66.28-139.88$ \\
\hline
\end{tabular}

Table 2: Analysis of variance table

\begin{tabular}{llllll}
\hline Source & DF & Sums of squares & Mean sum of squares & $F$ & $p$-value \\
\hline Between groups & 3 & 22225.86 & 7408.62 & 10.84 & $0.00076422^{*}$ \\
Residual & 13 & 8877.75 & 682.90 & - & - \\
Total & 16 & 31103.61 & - & - & \\
\hline
\end{tabular}

** Statistically Significant at $1 \%$ level of significance 


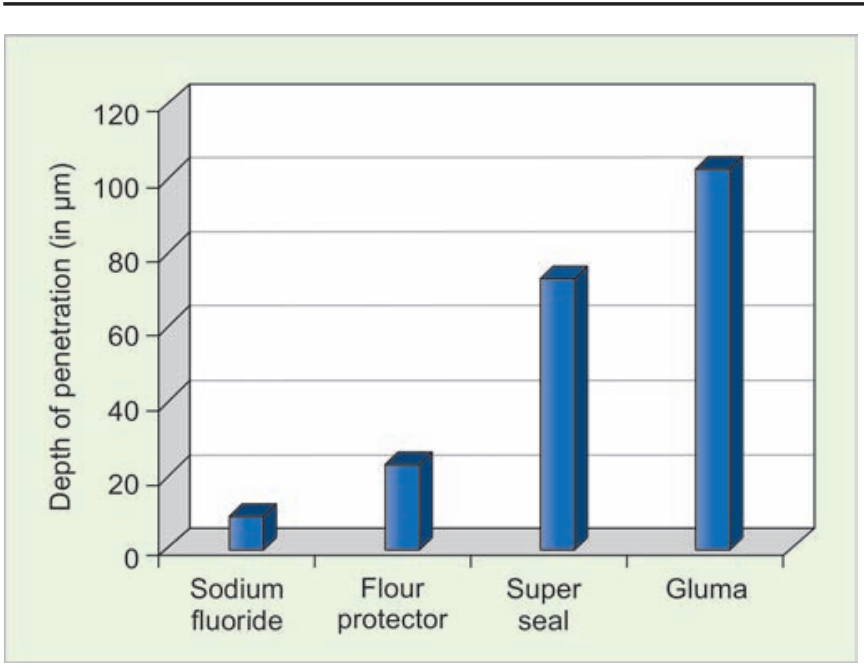

Graph 1: Depth of penetration of desensitizing agents (in $\mu \mathrm{m}$ )

Table 3: Difference of means

\begin{tabular}{lllll}
\hline & Mean & FluorProtector & SuperSeal & Gluma \\
\hline Sodium fluoride & 9.03 & 12.2 & $64.02^{\star}$ & $92.66^{\star \star}$ \\
FluorProtector & 21.23 & & $51.82^{\star}$ & $80.46^{\star \star}$ \\
SuperSeal & 73.05 & & & 28.64 \\
Gluma & 101.69 & & & - \\
\hline
\end{tabular}

${ }^{* *} p<0.01$, significant at $1 \%$ level of significance; ${ }^{*} p<0.05$, significant at $5 \%$ level of significance

significant difference was found between sodium fluoride and FluorProtector $(p>0.05)$. Mean depth of penetration of SuperSeal and Gluma was significantly higher than that of other two agents $(p<0.05)$. No significant difference was found between SuperSeal and Gluma ( $>>0.05)$ (Table 3).

\section{DISCUSSION}

This study was performed to evaluate the depth of penetration of different types of commercially available desensitizing agents within the dentinal tubule. The exposed patent dentinal tubule is considered the morphological etiology of dentin hypersensitivity; in vivo studies revealed ${ }^{4,5}$ the "hypersensitive" dentin has more widely open tubules as compared with "nonsensitive" dentin. The wider dentinal tubules increase the fluid movement and thus increase the pain/sensitivity response..$^{6-8}$ According to hydrodynamic theory, if the functional radius of opened dentinal tubules decreases, the permeability is also decreased, reducing dentin sensitivity. Occluding dental tubular agents can create a barrier by precipitating proteins and calcium/ phosphate ions on the surface or within the tubule orifice. ${ }^{9}$ The degree of desensitizing activity increases with the increase of depth of penetration, because if the penetration level is less, there is chance of removal of deposits by brushing or dietary acids, but if the penetration level is more within the dentinal tubule, the brushing or dietary acids can't easily remove it; it can occlude the dentinal tubule better and thereby give more desensitizing effect. ${ }^{10}$

The SEM study showed a wide range of depth of penetration within the dentinal tubule.

In the present study, Gluma showed highest depth of penetration $[(101 \pm 31.75)>$ SuperSeal $(73.05 \pm 33.60)>$ FluorProtector $(21.23 \pm 8.91)>$ sodium fluoride $(9.03 \pm 3.41)]$. From the result, it was found that the depth of penetration of SuperSeal and Gluma is significantly higher than FluorProtector and sodium fluoride.

Gluma desensitizer (Heraeus Kulzer, Hanau, Germany) contains Hydroxyethyl methacrylate (HEMA), benzalkonium chloride (BAC), glutaraldehyde, and fluoride. Glutaraldehyde reacts with the serum albumin in the dentinal fluid, causing its precipitation; HEMA forms deep resinous tags, which occlude the dentinal tubules. ${ }^{8,11}$ The BAC is an antiproteolytic agent with inhibitory effect on dentin matrix metalloproteinases (MMPs). The MMPs cause the degradation of collagen network of dentinal matrix and are responsible for dentin erosion and hypersensitivity. The BAC molecule binds strongly to demineralized dentin even after rinsing; thereby, it remains viable in the hybrid layer and exerts its anti-MMP properties. ${ }^{12}$ The presence of a dentinal smear layer had no appreciable effect on dentin sensitivity responses for Gluma (Felton 1991). ${ }^{13}$ Zaheed Mehmood et al reported that Gluma desensitizer showed better results in relieving dentinal hypersensitivity than Duraphat (fluoride varnish) in noncarious cervical lesions. ${ }^{14}$ Combination of resinous tag and protein precipitation is probably the reason of maximum penetration.

SuperSeal is a solution of potassium oxalate dehydrate. Potassium oxalate can remove the smear layer. ${ }^{15}$ Oxalates can occlude the dentinal tubules by reducing the permeability. Thirty percent $(30 \%)$ potassium oxalate had shown a $98 \%$ reduction of dentinal permeability. It has been shown that topical application of $3 \%$ potassium oxalate reduced hypersensitivity following the periodontal therapy. The oxalate ions react with the calcium ions of dentin-producing calcium oxalate crystals inside the dentinal tubules and also on the dentinal surface, resulting in a better sealing. ${ }^{3,8}$ Kolker et al reported SuperSeal is most beneficial when treating dentin sensitivity. Mean percent reduction in dentin permeability for SuperSeal was $97.5 \pm 4.0$, and this value was much higher than Seal \& Protect, Gluma Desensitizer, HurriSeal, D/Sense $2 .{ }^{16}$ This does not match with the present study.

FluorProtector in contact with the tooth surface causes a slow and continuous release of fluoride. The fluoride content is equivalent to $0.1 \%$, or 1,000 parts per million in solution. FluorProtector operates via sealing the open dentinal tubules. The low-viscosity varnish is able to penetrate well into the tubules and block the entrances mechanically. 
The fluoride is dissolved in an organic solvent, which evaporates after application, leaving a thin layer of the material covering the exposed tooth surfaces. The mechanism of action is the deposition of calcium fluoride on the tooth surface, with the formation of fluorapatite. ${ }^{1,8}$

The sodium fluoride solution deposits calcium fluoride crystals inside the dentinal tubules as well as on the dentin surface and thereby decreases the dentinal permeability. These crystals are partially insoluble in saliva. But these fluoride precipitates can be easily displaced and ultimately removed by oral fluids or can be mechanically removed by the action of toothbrush, which may explain the transitory action of this barrier. ${ }^{3,8}$

\section{CONCLUSION}

- In this study, the depth of penetration of resinous desensitizing agent (Gluma) is maximum followed by potassium oxalate solution (SuperSeal) and fluoride varnish (FluorProtector).

- Desensitizing effect of resinous desensitizing agent (Gluma) should be more than potassium oxalate solution (SuperSeal), fluoride varnish (FluorProtector), and sodium fluoride.

- Long-term clinical studies are required to correlate between in vitro and in vivo studies.

\section{REFERENCES}

1. Camilotti V, Zilly J, Busato Pdo M, Nassar CA, Nassar PO. Desensitizing treatments for dentin hypersensitivity: a randomized, split-mouth clinical trial. Braz Oral Res 2012 May-Jun;26(3):263-268.

2. Brännström M. Sensitivity of dentine. Oral Surg Oral Med Oral Pathol 1966 Apr;21(4):517-526.

3. Orchardson R, Gilliam D. Managing dentin hypersensitivity. J Am Dent Assoc 2006 Jul;137(7):990-998.

4. Guentsch A, Seidler K, Nietzsche S, Hefti AF, Preshaw PM, Watts DC, Jandt KD, Siqusch BW. Biomimetic mineralization: long-term observations in patients with dentin sensitivity. Dent Mater 2012 Apr;28(4):457-464.

5. Yoshiyama M, Masada J, Uchida A, Ishida H. Scanning electron microscopic characterization of sensitive vs insensitive human radicular dentin. J Dent Res 1989 Nov;68(11):1 498-1502.

6. Absi EG, Addy M, Adams D. Dentine hypersensitivity: A study of the patency of dentinal tubules in sensitive and non-sensitive cervical dentine. J Clin Periodontol 1987 May;14(5):280-284.

7. Rimondini L, Baroni C, Carrassi A. Ultrastructure of hypersensitive and non-sensitive dentine. A study on replica models. J Clin Periodontol 1995 Dec;22(12):899-902.

8. Miglani S, Aggarwal V, Ahuja B. Dentin hypersensitivity: Recent trends in management. J Conserv Dent 2010 Oct;13(4): 218-224.

9. Pinto SC, Pochapski MT, Wambier DS, Pilatti GL, Santos FA. In vitro and in vivo analyses of the effects of desensitizing agents on dentin permeability and dentinal tubule occlusion. J Oral Sci 2010 Mar;52(1):23-32.

10. Arrais CA, Chan DC, Giannini M. Effects of desensitizing agents on dentinal tubule occlusion. J Appl Oral Sci 2004 Jun;12(2):144-148.

11. Dondi dall'Orologio G, Lone A, Finger WJ. Clinical evaluation of the role of glutardialdehyde in a one-bottle adhesive. Am J Dent 2002 Oct;15(5):330-334.

12. Tezvergil-Mutluay A, Mutluay MM, Gu LS, Zhang K, Agee KA, Carvalho RM, Manso A, Carrilho M, Tay FR, Breschi L, et al. The anti-MMP activity of benzalkonium chloride. J Dent 2011;39(1):57-64.

13. Felton DA, Bergenholtz G, Kanoy BE. Desensitizing effect of Gluma on prepared tooth. Int J Prosthodont 1991 MayJun;4(3):292-298.

14. Mehmood Z, Shah JA, Javed MU, Manzoor MA, Asghar I, Saeed MH. Efficacy of Gluma Desensitizer and Duraphat in relieving dentinal hypersensitivity in non-carious cervical lesions. Pakistan Oral Dent J 2011 Jun;31(1):183-186.

15. Pashley DH, Galloway SE. The effects of oxalate treatment on smear layer of ground surfaces of human dentine. Arch Oral Biol 1985;30(10):731-737.

16. Kolker JL, Vargas MA, Armstrong SR, Dawson DV. Effect of desensitizing agents on dentin permeability and dentin tubule occlusion. J Adhes Dent 2002;4(3):211-221. 